\title{
Interés superior del niño: técnicas de reducción de la discrecionalidad abusiva. Farith Simon (2014). Quito: Ed. Iuris Dictio.
}

\author{
Sonia Merlyn Sacoto \\ Pontificia Universidad Católica del Ecuador
}

Farith Simon Campaña, jurista ecuatoriano de renombrada trayectoria, ha dedicado los últimos ańos su labor a la docencia e investigación jurídica, en especial dentro del área de Nińez y Adolescencia. Fruto de ésta ha sido la publicación en el año 2014 de la obra titulada: Interés superior del niño: técnicas de reducción de la discrecionalidad abusiva.

En esta última obra (que de algún modo es una segunda parte del libro Derechos de la Niñez y Adolescencia: de la Convención sobre los Derechos del Niño a las legislaciones integrales $)^{1}$, el autor realiza un análisis detallado sobre el interés superior de los niños y adolescentes, que demuestra su experticia en la materia. En ella, plasma su aporte personal de manera original al identificar varias técnicas, cuyo uso recomienda para reducir la discrecionalidad abusiva en la aplicación del interés superior por parte de los juzgadores.

La redacción, aunque sobria, denota creatividad sin arrogancia y, de manera impecable, permite comprender conceptos jurídicos relevantes que aún no habían sido abordados por la doctrina ecuatoriana. Al leer su texto, pese a que el autor modestamente indica que los límites espaciales de su investigación son Ecuador, Colombia, Perú, Bolivia y España, en realidad tenemos la impresión de realizar un paseo centrado en temas de niñez por varios sitios del mundo. Justamente, de manera didáctica se aborda el principio del interés superior, su importancia y sentido, conservando siempre como ejes transversales la jurisprudencia y la doctrina sobre el tema no sólo de los Estados citados por el autor, sino también de otros Estados latinoamericanos (Chile, El Salvador, entre otros) y europeos como Italia y Alemania, e inclusive países que integran el Common Law.

La obra se encuentra estructurada en cinco capítulos. En el primer capítulo, el autor explica el impacto que ha tenido la normativa internacional en la creación del interés superior. De esta manera, expone que es en el año de 1959 cuando se encuentra por primera vez mencionado en la Declaración de los Derechos del Niño de las Naciones Unidas y se realiza una breve, pero exhaustiva, revisión de todos los instrumentos internacionales que tratan sobre el interés superior. Esto último con especial atención a la Convención de Derechos del Niño de Naciones Unidas (1989), por su aporte al modificar la consideración jurídica de los niños, niñas y adolescentes, que se resume en dos aspectos esenciales: la titularidad y el ejercicio progresivo de los derechos. En este mismo capítulo se analiza también, la forma como han aplicado e interpretado el interés superior los tribunales internacionales de derechos humanos en su jurisprudencia. A la vez, el autor nos aclara un asunto aparentemente simple como las discrepancias terminológicas entre el uso de la palabra "menores" y el de "nińas, niños y adolescentes", para lo cual indica que el término "menores" se ha ligado en Latinoamérica con prejuicios y la estigmatización discriminatoria por motivos de edad, a diferencia de Espańa y el resto de Europa, en donde se usa sin adquirir dicha connotación, por lo que dichas expresiones son usadas dentro de la obra indistintamente.

Aunque el segundo capítulo es el menos extenso de la obra, en él Simon nos introduce en el punto medular de ésta, pues nos permite comprender la doble dimensión de la técnica jurídica (elaboración del lenguaje jurídico y de la normativa) y explica los modos para acceder a ella: o bien desde una versión minimalista, que sólo atiende a su calidad lingüística y

${ }^{1}$ El libro tiene dos tomos. El primero fue publicado en 2009 y el segundo en 2009. 
sistemática; o, por el contrario, desde una versión maximalista, que incluye los valores y fines de la legislación, visión que el autor considera fundamental para comprender la forma como el interés superior es integrado en cada legislación. Posteriormente, resume para el lector las principales técnicas destinadas a la regulación del interés superior, partiendo de la técnica de cláusula general aplicada en Espańa, Italia y Alemania, a la cual distingue de los principios jurídicos indeterminados, entre los cuales incluye el interés superior. Seguidamente revisa la técnica de la concreción del interés superior del niño, mediante criterios a ser considerados para las decisiones judiciales, tomando en cuenta las condiciones específicas de cada nińo. Asimismo, señala una técnica que debe aplicarse de modo excepcional, proveniente de las situaciones preestablecidas normativamente como favorables para el interés superior, para concluir con aquella de la equiparación del mejor interés del niño con sus derechos. En este capítulo de gran interés, resalta la diferencia identificada con claridad por el autor entre las reglas jurídicas normas que nos indican cómo actuar y los principios jurídicos que brindan criterios para tomar posición ante situaciones concretas; diferenciación imprescindible para quien aplica ambos pues los últimos requieren de una evaluación de peso e importancia.

En el siguiente capítulo, nos aproxima a la doctrina contemporánea mundial sobre el interés superior. Se cita así a autores como el chileno Miguel Cillero Buñol, el sudafricano, de nacimiento, aunque británico de formación, John Eekelaar, las propuestas del francés Gilles Lebreton, entre otros. Farith Simon explica como la doctrina en general coincide en la imposibilidad de definir de manera concreta el interés superior. A partir de esta consideración, intenta resumir los conceptos que se han ensayado, entre ellos destaca el de la profesora española Susana Navas Navarro y el del suizo Jean Zermatten, para terminar con la revisión de las cinco manifestaciones normativas que permiten identificar las propuestas doctrinales que ha comentado sobre el interés superior (es decir, como criterio de prioridad o prevalencia sobre otros intereses; como criterio garantista para asegurar la vigencia de los intereses de los nińos, niñas y adolescentes; como criterio informador que otorga directrices para conseguir fines constitucionales; como elemento de integración para llenar lagunas normativas; y finalmente, elemento de interpretación normativa).

El cuarto capítulo de Interés superior del niño: técnicas de reducción de la discrecionalidad abusiva está dedicado al análisis del rol de la argumentación, la interpretación y la fundamentación de las decisiones judiciales en la búsqueda de la aplicación racional del interés superior, tomando en cuenta a éste como principio jurídico indeterminado deliberadamente por el legislador para permitir la flexibilidad de la norma frente a cada caso, por lo que concede discrecionalidad al juzgador. A fin de que la seguridad jurídica no se vea afectada y la discrecionalidad no se convierta en arbitrariedad, el autor enfatiza la necesidad de motivar/justificar las decisiones judiciales en las que interviene el interés superior de los niños, puesto que califica estos casos como difíciles, en los que el juzgador debe refinar las reglas de interpretación. Para esto toma una forma similar a la estructura del razonamiento judicial, que se despliega cuando se efectúa el llamado test de proporcionalidad, como proceso adjudicativo de derechos, para evitar así que este principio se convierta en el escudo de las preferencias o convicciones propias de quien lo aplica y pierda así su finalidad.

Finalmente, el quinto capítulo presenta un análisis actualizado sobre el principio del interés superior en el Derecho Comparado, tanto a nivel legislativo como jurisprudencial, con especial énfasis en los países de la región andina y España.

Concluye Farith Simon en su obra que el principio del interés superior es indeterminado pero no incierto, por lo que considera necesario que se combinen varias técnicas a fin de limitar la discrecionalidad abusiva en las decisiones judiciales.

$\mathrm{Al}$ lector le conviene no desdeñar la abundante información contenida en las notas 
al pie de página a lo largo de toda la obra comentada, en donde encontrará desde el extracto seleccionado con inmejorable criterio jurídico de varios fallos de los tribunales regionales de derechos humanos hasta el texto completo de artículos de las leyes invocadas en materia de niñez a nivel mundial, al igual que valiosos comentarios del autor sobre los diversos temas tratados.

Esta obra se constituye así en el referente obligatorio para todos los docentes, alumnos, jueces y litigantes que a diario practicamos el Derecho de Nińez y Adolescencia, quienes por fin contamos con una obra actualizada sobre un tema que palpita a diario en los tribunales y en el centro del Derecho de Familia, Niñez y Adolescencia, cuyo análisis tradicionalmente ha sido desdeńado en el Ecuador y que, gracias a este valioso trabajo, ha adquirido la relevancia que amerita su estudio. 
